\title{
CÂNCER DE MAMA E IMAGEM CORPORAL: IMPACTO DOS TRATAMENTOS NO OLHAR DE MULHERES MASTECTOMIZADAS
}

Tamara Rodrigues de Oliveira

Graduada em Fisioterapia pela Universidade Federal de Juiz de Fora (UFJF) Brasil.

\section{Camila Soares Lima Corrêa}

Doutoranda no Programa de Pós-Graduação em Saúde Coletiva da UFJF Brasil.

\section{Vinícius Faria Weiss}

Mestre em Ciências da Reabilitação e Desempenho Físico Funcional pela UFJF Brasil.

Ana Paula de Sousa Silva Baquião

Doutoranda no Programa de Pós-Graduação do departamento de Psicologia da Universidade Federal de Juiz de Fora Brasil.

\section{Laís Lage de Carvalho}

Doutoranda no Programa de Pós-Graduação do departamento de Psicologia da UFJF Brasil.

\section{Fabiane Rossi dos Santos Grincenkov}

Doutora em Saúde pela UFJF e docente no Programa de Pós-Graduação em Psicologia da UFJF Brasil

\section{Simone Meira Carvalho}

Doutoranda no Programa de Pós-Graduação do departamento de Psicologia da UFJF e docente no departamento de Fisioterapia do Idoso, do Adulto e Materno-Infantil da Faculdade de Fisioterapia da UFJF Brasil
RESUMO: Esta pesquisa avaliou a percepção da imagem corporal de mulheres mastectomizadas, com ou sem reconstrução mamária, investigando como o adoecimento e os tratamentos impactaram suas vidas. Trata-se de um estudo descritivo, transversal, com abordagem qualitativa. Participaram dez mulheres com diagnóstico de câncer mamário, mastectomizadas, com ou sem reconstrução mamária, atendidas no HU/UFJF, de janeiro a novembro de 2015, por meio de uma entrevista semiestruturada. Para análise qualitativa, aplicou-se a Análise de Conteúdo de Bardin, de onde emergiram as categorias: "Diagnóstico e Enfrentamento", "Rede de Apoio", "Tratamentos e seus Anseios", "Imagem Corporal", e "Papel na Sociedade". Concluiuse que o cuidado com a saúde das mulheres acometidas pela doença demanda assistência multiprofissional, que auxilie no processo de enfrentamento do câncer e na reabilitação para além das limitações físicas, com o intuito de reconexão do corpo físico, psíquico e espiritual, visando facilitar a adaptação ao "novo corpo" e permitir incremento na autoestima, a reinserção social e melhoria da qualidade de vida.

PALAVRAS-CHAVE: Imagem corporal; Neoplasias da mama; Mastectomia; Fisioterapia.

\section{BREAST CANCER AND BODY IMAGE: IMPACT OF TREATMENTS FROM THE POINT OF VIEW OF MASTECTOMIZED FEMALES}

\begin{abstract}
The perception of body image by mastectomized females, with or without breast reconstruction, is evaluated. Current descriptive, transversal and qualitative research analyzes how illness and treatments impacted their lives. Ten mastectomized females, diagnosed with breast cancer, attended at the University Hospital of UFJF, between January and November 2015, participated through a half-structured interview. Qualitative analysis comprised Bardin's Content Analysis, from which were derived the categories: "Diagnosis and Coping", "Support Network", "Treatments and Anxiety", "Body Image", and "Role in Society". Results show that health care of ill females require multiprofessional assistance that helps them to cope with cancer and to rehabilitate them beyond physical limitations. The target is the reconnection of the physical, psychic and spiritual body, to facilitate the adaptation to the 'new body' and allow an increase in self-esteem, social reinsertion and improvement in life quality.
\end{abstract}

KEY WORDS: Body image; Breast Neoplasms; Mastectomy; Physical Therapy Specialty. 


\section{INTRODUÇÃO}

$\mathrm{O}$ câncer de mama é a neoplasia maligna mais comum entre as mulheres na maior parte do mundo. As estatísticas apontam uma estimativa de 2,1 milhões de novos casos, em nível mundial, e 59.700 novos casos, no Brasil $^{1}$. Conforme o INCA ${ }^{2}$, no Brasil, as taxas de incidência variam entre as diferentes regiões do país, tendo as regiões Sul $(73,07 / 100 \mathrm{mil})$ e Sudeste $(69,50 / 100 \mathrm{mil})$ mais altas. As taxas de mortalidade permanecem elevadas no Brasil, o que pode ser justificado pelo diagnóstico tardio da doença ${ }^{2}$. Quando diagnosticado e tratado precocemente, o câncer de mama apresenta, na maioria dos casos, um bom prognóstico ${ }^{1,2,3}$. Para Brochonski et al. ${ }^{3}$, o diagnóstico precoce é uma tarefa complexa, já que existem diversas barreiras institucionais - como a integração entre os setores de saúde -, e poucas são as ferramentas que podem ser aplicadas para busca ativa das mulheres atingidas pela doença.

A alta incidência da doença e os seus efeitos, como a desfiguração da mama e, consequente, alteração da imagem corporal, tornam esse tipo de neoplasia um dos mais temidos pelas mulheres ${ }^{3,4,5}$. A forma como a mulher vivencia o adoecimento por câncer mamário afetará suas relações sociais em geral, repercutindo em estados de depressão e podendo desencadear modificações nos hábitos de vida ${ }^{4,6,7,8}$. Com isso, após a confirmação do diagnóstico, a mulher se depara com dois problemas: o medo do câncer e seu estigma de doença terminal, e a possível mutilação de uma parte exclusiva do corpo feminino $0^{6,9,10,11}$.

O tratamento do câncer de mama é multidisciplinar e pode envolver tratamento cirúrgico, sistêmico (quimioterapia, hormonioterapia e imunoterapia), radioterapia e reabilitação tanto física quanto psicológica $^{1,12}$. O principal objetivo é eliminar o tumor e bloquear suas vias de drenagem (linfonodos), quando necessário. A retirada dos linfonodos axilares pode ocasionar o linfedema (edema crônico que se instala alguns meses após o tratamento cirúrgico), com alteração da simetria corporal e da movimentação do braço ${ }^{12,13}$.

A maioria das mulheres diagnosticadas com esse tipo de tumor passa por uma intervenção cirúrgica para retirada parcial ou total da mama (mastectomia), muitas vezes considerada traumatizante, já que altera sua aparência, sensibilidade e funcionalidade ${ }^{12,14}$. Seus resultados - associados ou não a tratamentos complementares - podem causar efeitos colaterais, afetando-as física, social e emocionalmente ${ }^{4,12,14}$. Os efeitos psicológicos gerados pelo impacto do diagnóstico e dos tratamentos provocam mudanças na vida dessas mulheres que vão desde suas atividades diárias ${ }^{7,14,15} \mathrm{e}$ convívio social até sua sexualidade e percepção da própria imagem corporal ${ }^{3,11,16}$.

A forma como o corpo é representado exerce papel fundamental na construção da autoimagem ${ }^{4,9}$. A maneira como a mama é observada na sociedade contribui para que ela seja cada vez mais valorizada, podendo influenciar no desenvolvimento e na formação da imagem corporal das mulheres ${ }^{9}$. Qualquer mudança nessa área desencadeia questionamentos a respeito da identidade feminina ${ }^{3,4,9}$. A mama é associada à identificação da mulher com a sua feminilidade, simbolizando fertilidade, aleitamento e sexualidade ${ }^{9,15}$; possui também importância social pela sua visibilidade, em especial na cultura contemporânea que supervaloriza aquilo que se destaca na mídia, como as mamas que aparecem em roupas cada vez mais decotadas ${ }^{8,9}$.

A imagem corporal é conceituada como a maneira que imaginamos nosso corpo e como ele é representado mentalmente para nós mesmos ${ }^{8,9}$. Essa representação da nossa mente não é apenas a da imagem que é refletida no espelho (corpo físico), mas a imagem de um corpo cheio de significados, estabelecidos pelas percepções e experiências diárias, a ideia que cada um tem de seu corpo no contexto em que vive ${ }^{8,9,17}$. Trata-se de um conceito amplo que envolve aspectos fisiológicos, psicológicos, sociais e culturais ${ }^{917}$. Compreender a imagem corporal em mulheres com neoplasia mamária é fundamental para o entendimento do estresse causado pelas alterações resultantes da doença e seus tratamentos, do modo como essas mulheres reagem às mudanças físicas, aos problemas psicossociais e, ainda, como enfrentam esse processo $0^{9,18,19}$. Com isso, tornam-se crescentes as pesquisas em imagem corporal, a fim de entender melhor como a doença afeta a mulher e como melhorar a assistência.

A cirurgia, assim como os demais tratamentos, pode deixar sequelas limitantes ${ }^{7,11}$. Para diminuir seus 
impactos na vida da mulher, torna-se necessário um acompanhamento multiprofissional ${ }^{16}$. A reabilitação tem como objetivo melhorar a qualidade de vida, atendendo às necessidades individuais por meio da restauração da integridade física, mental e funcional ${ }^{7,12,19}$. De acordo com a Organização Mundial da Saúde, a funcionalidade é um indicador importante de saúde, que busca adotar uma abordagem biopsicossocial, englobando a interação entre os vários aspectos da saúde, a saber: biológico, individual e social ${ }^{12}$. O impacto na funcionalidade pode gerar o abandono de algumas atividades cotidianas ${ }^{4,13}$, desencadeando um sentimento de incapacidade e distúrbios emocionais que afetam a qualidade de vida das mulheres ${ }^{12,14}$.

É importante a busca por uma nova perspectiva de assistência às mulheres com câncer mamário, uma vez que essa condição suscita necessidades que vão além do fator físico, englobando igualmente fatores psicossociais. Com isso, é relevante abordar a imagem corporal dessas mulheres, a fim de chamar a atenção dos profissionais e acadêmicos de saúde para a importância das questões psicossociais e a importância de sua atuação, durante a reabilitação, no processo de reconstrução da autoimagem. Deste modo, o estudo buscou compreender a percepção da imagem corporal de mulheres mastectomizadas, com ou sem reconstrução mamária, reconhecer como as mulheres mastectomizadas vivenciam a relação com o "novo corpo", como os tratamentos podem afetar a vida dessas mulheres e influenciar no impacto dos tratamentos e no processo de reconstrução da imagem corporal.

\section{METODOLOGIA E ESTRATÉGIAS DE AÇÃO}

Trata-se de um estudo do tipo descritivo, de corte transversal, com abordagem qualitativa. O objeto de estudo insere-se no campo da subjetividade e pretendeu entender o significado e a intencionalidade de discursos e práticas quanto às representações do corpo das mulheres mastectomizadas, bem como o impacto dos tratamentos do câncer de mama. Ou seja, preocupou-se com um nível de realidade que não pode ser quantificado, trabalhando com o universo de significados, motivos, valores e atitudes ${ }^{20}$.

A amostra foi escolhida por conveniência e composta por mulheres com diagnóstico de câncer de mama, mastectomizadas, com ou sem reconstrução mamária (imediata ou tardia), atendidas no ambulatório de Fisioterapia do Hospital Universitário (HU), Unidade Dom Bosco, da Universidade Federal de Juiz de Fora (UFJF), em Juiz de Fora, Minas Gerais, no período de janeiro a novembro de 2015.

Por meio da técnica de saturação da amostra, alcançou-se um total de dez mulheres, cujos dados foram divididos em dois grupos para a análise: Grupo I, formado por cinco mulheres que fizeram a mastectomia sem reconstrução; Grupo II, formado por cinco mulheres que fizeram a mastectomia com reconstrução.

Os critérios de inclusão propostos foram: mulheres, com diagnóstico de câncer de mama, submetidas à mastectomia, somente em uma das mamas; estando ou não em tratamento; com idade mínima 18 anos. Não foram incluídas as participantes que apresentassem algum tipo de comprometimento cognitivo que pudesse interferir na coleta dos dados e inviabilizar a pesquisa; e que estivessem com metástases da doença.

Foram realizadas entrevistas individuais, semiestruturadas, que foram gravadas e, posteriormente, transcritas, e analisadas por meio da análise de conteúdo temática proposta por Bardin ${ }^{21}$, que consiste em descobrir os núcleos de sentido que compõem uma comunicação cuja presença ou ausência signifiquem alguma coisa para o objetivo visado.

O projeto foi aprovado pelo Comitê de Ética da UFJF (parecer 1.047.539, 04/05/2015), de acordo com a resolução $n^{0} 466 / 2012$, do Conselho Nacional de Saúde, do Ministério da Saúde ${ }^{22}$. Os participantes foram informados dos objetivos do estudo e assinaram o Termo de Consentimento Livre e Esclarecido (TCLE). Para garantir a privacidade das participantes, os recortes das falas das entrevistadas foram identificados pela letra E, seguida de número arábico, conforme a sequência das entrevistas. 


\section{RESULTADOS E DISCUSSÃO}

\section{PERFIL DAS ENTREVISTADAS}

A idade das entrevistadas variou de 39 a 63 anos. Elas foram distribuídas em dois grupos: o Grupo I (GI) foi composto por cinco pacientes que realizaram a mastectomia sem reconstrução, com idade média de 54,2 ( \pm 5,3 anos). O Grupo II (GII) também foi composto por cinco mulheres, porém que já haviam passado pela cirurgia de reconstrução mamária, com idade média de 49,6 ( \pm 9 anos). A Tabela 1 apresenta a distribuição dos grupos com outras informações.

Tabela 1. Perfil sociodemográfico das mulheres

\begin{tabular}{lllll}
\hline \multicolumn{5}{l}{ GRUPO I - CIRURGIA DE MAMA SEM RECONSTRUÇÃO } \\
\hline Vol. & Idade & Estado Civil & Escolaridade & Situação \\
\hline E1 & 54 & Viúva & $2^{\circ}$ grau completo & Ativa \\
E2 & 63 & Viúva & $1^{\text {o }}$ grau incompleto & Aposentada \\
E3 & 50 & União estável & $1^{\text {o }}$ grau completo & Aposentada \\
E8 & 54 & Solteira & $1^{\text {o }}$ grau incompleto & Aposentada \\
E9 & 50 & Casada & $2^{\text {o }}$ grau incompleto & Afastada \\
\hline
\end{tabular}

GRUPO II - CIRURGIA DE MAMA COM RECONSTRUÇÃO

\begin{tabular}{lllll}
\hline Vol & Idade & Estado Civil & Escolaridade & Situação \\
\hline E4 & 39 & Namorando & $1^{\circ}$ grau incompleto & Afastada \\
E5 & 45 & Divorciada & $1^{\mathrm{o}}$ grau completo & Ativa \\
E6 & 63 & Casada & $1^{\mathrm{o}}$ grau incompleto & Aposentada \\
E7 & 53 & Casada & $1^{\mathrm{o}}$ grau incompleto & Afastada \\
E10 & 48 & Casada & $2^{\mathrm{o}}$ grau completo & Ativa \\
\hline
\end{tabular}

Nota: Vol = Voluntária

Com relação ao perfil clínico das participantes, o tempo de realização da mastectomia variou de 1 a 14 anos. No GI, o tempo médio de cirurgia foi de 2,6 $( \pm 2)$ anos; duas das cinco entrevistadas expressaram o desejo de realizarem a reconstrução mamária e todas utilizavam prótese externa. No GII, o tempo de realização da primeira cirurgia foi de 5,2 ( \pm 5,7) anos; das cinco mulheres que realizaram a reconstrução, duas foram realizadas de forma imediata e três tardiamente. Quanto aos tratamentos adjuvantes à cirurgia, $90 \%$ das voluntárias realizaram a quimioterapia $(\mathrm{Q}), 60 \%$ realizaram tanto a radioterapia (R) quanto à hormonioterapia $(\mathrm{H})$, sendo que apenas $40 \%$ ainda estavam passando por esse último. A Tabela 2 apresenta as características clínicas.
Tabela 2. Perfil clínico das mulheres

\begin{tabular}{llll}
\hline \multicolumn{3}{l}{ GRUPO I - CIRURGIA DE MAMA SEM RECONSTRUÇÃO } \\
\hline Vol. & Ano da cirurgia & Tratamentos adjuvantes & Prótese externa \\
\hline E1 & 2013 & Q-R - H & Sim \\
E2 & 2014 & Q & Sim \\
E3 & 2012 & Q & Sim \\
E8 & 2009 & Q-R - H & Sim \\
E9 & 2014 & Q-R - H & Sim \\
\hline
\end{tabular}

GRUPO II - CIRURGIA DE MAMA COM RECONSTRUÇÃO

\begin{tabular}{llll}
\hline Vol. & Ano da cirurgia & Tratamentos adjuvantes & Reconstrução \\
\hline E4 & 2014 & Q - R & Imediata \\
E5 & 2013 & H & Tardia \\
E6 & 2001 & Q - R - H & Tardia \\
E7 & 2007 & Q & Tardia \\
E10 & 2014 & Q - R - H & Imediata \\
\hline
\end{tabular}

Nota: Vol $=$ Voluntária

\section{ANÁLISE DAS ENTREVISTAS}

Para facilitar a compreensão da análise, foram divididas cinco grandes categorias, que surgiram das unidades de registro. Essas unidades serão posteriormente expostas, de acordo com as respectivas categorias: "Diagnóstico e enfrentamento", "Rede de apoio", "Tratamentos e seus anseios", "Imagem corporal" e "Papel na sociedade".

\section{DIAGNÓSTICO E ENFRENTAMENTO}

Esta categoria foi construída a partir das subcategorias: "receber a notícia", "enfrentamento", "aceitação", "estigma da morte" e "questionamentos".

As falas das participantes denotaram um misto de emoções positivas e negativas frente ao diagnóstico, como observado nos relatos de E2 e E9. Corroborando os dados encontrados, Inocenti et al. ${ }^{5}$, Martins, Ouro e $\mathrm{Neri}^{17}$ e Carvalho et $a .^{19}$ observam que a confirmação do câncer de mama pode desencadear reações que variam de acordo com a história de cada mulher e a fase do tratamento na qual se encontra. Neste sentido, os sentimentos despertados podem ser de desespero, tristeza e até alívio. Inocenti et al. ${ }^{5}$ e Silva et al. ${ }^{8}$ relatam que, no decorrer do tratamento, os sentimentos mudam, podendo ser, inicialmente, de perda, de desânimo ou de aceitação, até chegarem às fases finais, quando as mulheres se sentem satisfeitas ou vitoriosas com a ideia da cura. 
O mundo acabou para mim. Falei: "Agora não tem mais jeito a minha vida, só Deus para me ajudar". (E2)

Foi mais um alívio. Porque eu já tinha a desconfiança e, então, eu pensei, que agora, sabendo o que é, a gente vai tratar, né, vai direto para o tratamento. (E9)

As verdades e os mitos que cercam o câncer de mama no conhecimento popular vêm à tona com a confirmação do diagnóstico ${ }^{19}$. Ainda hoje, o câncer carrega o estigma de uma doença maligna. A ideia de morte vem como um dos primeiros pensamentos após o diagnóstico ${ }^{8}$, acarretando sentimentos de ansiedade e depressãa ${ }^{15}$. O tabu em relação à doença também é citado por duas participantes do presente estudo.

Você não quer pensar. Você vai pensar na morte, porque, até então, o câncer mata, né? Você não tem outra resposta para o câncer. Câncer é você e a morte; então, eu pensei que ia morrer. (E3)

"Nossa, ela está com câncer, ela vai morrer". Igual eu falei; antigamente, ninguém falava a palavra câncer, era um tabu. (E5)

Diante dessa nova situação, algumas mulheres buscam o entendimento para o surgimento do câncer e, muitas vezes, questionam e refletem sobre o motivo de sua doença, como reforçam os pressupostos de Martins, Ouro e $\mathrm{Neri}^{17}$. A fala a seguir denota este questionamento.

Você quer saber, "Meu Deus, mas por que eu?", né? E eu era uma pessoa assim, estava assim certinha; de 6 em 6 meses, sempre fazendo controle, sempre tendo aquele cuidado, sabe, e de repente, aparece. (E7)

Aprender a conviver com o câncer de mama é um processo contínuo e dinâmico, no qual as mulheres criam estratégias para lidar com as incertezas da doença ao longo da vida ${ }^{4}$. Com o decorrer dos tratamentos, elas adotam formas de enfrentamento que as ajudam a tornar essa jornada mais fácil ${ }^{4,19}$. Em ambos os grupos, a maioria das mulheres optou por confrontar a doença e os tratamentos de maneira positiva, umas se apegando à fé, outras à ideia de que tudo acontece por um motivo, apoiando os achados de outros autores ${ }^{8,18,19}$. Independente do modo de encarar a situação, todas procuraram enfrentar a doença de forma menos dolorosa.

Deixa a vida me levar, do jeito que ela me levar, está bom. E levei o tratamento como uma coisa natural. (E1)

[...] Eu não tenho como não aceitar, porque eu não posso passar para a porta do vizinbo, né? Veio aqui para mim, vamos lutar. (E7)

A aceitação surge como uma parte do processo de enfrentamento, uma forma de defesa para se adaptar à nova condiçãó ${ }^{4}$. A maioria prefere, conscientemente ou não, assumir um papel de conformação e aceitação do câncer, uma vez que elas percebem que sentimentos negativos dificultam o tratamento $0^{8,18,19}$. Tanto as mulheres do GI quanto do GII relataram que, com o tempo, aprenderam a lidar e aceitar sua condição, concluindo que a doença trouxe algo positivo.

Eu acho que tudo que acontece na vida da gente tem um por que [...]. Eu acho que, dentro disso tudo, a gente leva uma missão, entendeu? [...] E, depois que isso aconteceu comigo, eu fiquei muito mais solidária. (E1)

[...] No início que foi difícil, né, que a gente não aceita a doença, mas depois falei assim: "Deus deve ter algum plano para mim". [...] Eu vejo que Deus tinha esse propósito, para eu poder dar força pras pessoas que estão passando por isso. (E10)

\section{REDE DE APOIO}

Esta categoria emergiu das subcategorias: "apoio da fé", "apoio da família" e "apoio de terceiros".

O diagnóstico provoca, muitas vezes, um turbilhão de emoções que pode se intensificar, agravando a situação quando a mulher não encontra suporte emocional, atenção e apoio ${ }^{12,16}$. As mulheres buscaram diferentes fontes de apoio para enfrentar a doença, desde a fé em Deus, amparo da família, de amigos e vizinhos, de grupos de apoio e até dos profissionais de saúde que as acompanharam ${ }^{11}$. Alguns autores ${ }^{8,16,19}$ afirmam que a fé e o otimismo são estratégias de enfrentamento fundamentais 
em situações difíceis ocasionadas pelo câncer, pois proporcionam esperança e força, permitindo que as mulheres lidem de maneira diferente com a doença. Sete entrevistadas afirmaram que confiar em Deus lhes infundiu força em todos os momentos.

[...] Eu me entreguei muito mais a religião a partir daquele momento [...]. O que me fortaleceu foi isso, a minha fé realmente, pois em bora nenbuma eu tive medo. (E1)

Não sou católica, não sou evangélica, não sou macumbeira e não sou feiticeira, não sou nada, mas eu acreditei em Deus. (E4)

Com relação ao apoio familiar, para essas mulheres, é importante a forma como a família reage ao diagnóstico, pois esse é um recurso externo de grande relevância, uma vez que se trata do núcleo primário na vida das pessoas ${ }^{10,16,19}$. Para quase todas as entrevistadas, a família serviu de amparo frente aos momentos mais difíceis e lhes deu força, favorecendo seus tratamentos e uma readaptação mais saudável à nova condição de saúde.

Eu fui muito paparicada. Pela minha filba, meu genro, minha cunbada, meu marido. São as pessoas que mais me acompanbaram. (E3)

Por isso que eu falo: a família, os amigos, é cada um telefonando, ligando, mensagens, indo lá. [...] A família é a base de tudo, porque não é brinquedo. (E7)

A despeito disso, algumas mulheres não se sentiram amparadas pela família, como cita E8. Koch et al. ${ }^{15}$ enfocam que o adoecimento por câncer afeta tanto a pessoa acometida como a família, a qual também pode passar por momentos de angústia com a possibilidade da morte ou da mutilação de sua família.

[...] Eu não vou dizer que da família recebi muito apoio não [...]. Minbas irmãs, a única coisa que elas fizeram foi ficar dentro de casa, né? Não me deram, assim, uma palavra de conforto. (E8)

O apoio e a compreensão dos companheiros também são importante na recuperaçã $0^{5,10,11,12}$, pois aquelas que foram mastectomizadas e receberam carinho e acolhimento apresentaram melhor readaptaçã $0^{19}$. Já a ausência de apoio do companheiro pode desestimular a adesão ao tratamento ${ }^{19}$. Seis entrevistadas possuem companheiros e, dessas, quatro destacaram o apoio deles.

\begin{abstract}
[...] Na semana que eu fiz a cirurgia, ele colocou aliança no meu dedo [...]. "Hoje os bomens, geralmente, largam as mulberes que estão com a doença, e você está tendo todo esse apoio" [disse a psicóloga]. (E3)

Ele [marido] me deu muita força. Desde o início até o fim, ele me deu muita força. Ficou do meu lado. (E10)
\end{abstract}

Além dos familiares, é fundamental o apoio de outras pessoas, como amigos, vizinhos e a equipe de saúde durante o processo de enfrentamento da doença ${ }^{8,17,19}$. Duas entrevistadas tiveram apoio de grupos compostos por mulheres que também tinham o diagnóstico de câncer de mama. Dias et al..$^{10}$, Costa et al..$^{12}$, Farias et al. ${ }^{16}$ e Koch et al. ${ }^{15}$ salientam que as intervenções dos profissionais de saúde e a participação em grupo de apoio colaboram no processo de reabilitação. Quatro participantes do estudo citaram o apoio dos profissionais que as acompanharam, e outras duas citaram o carinho de vizinhos e amigos como importantes fatores de apoio.

\section{Tive muito apoio, não posso reclamar. [...] Todos [profissionais de saúde] me trataram muito bem, até além do limite, que não acreditava merecer tudo isso. (E2)
No GAI [Grupo de Acompanhamento Integrado] [...], a gente conversa, trocando ideia, uma levantando o astral das outras. [...] Foi muito importante. (E6)

Independente do tipo de apoio, ele é indispensável para que as mulheres encarem da melhor forma o tratamento, se readaptem e reorganizem sua vida da melhor maneira possível. Toda essa rede é uma estratégia para que os obstáculos e limites enfrentados pelo adoecer sejam minimizados ${ }^{11,17}$. 


\section{TRATAMENTOS E SEUS ANSEIOS}

Essa categoria foi construída a partir das subcategorias: "medo da cirurgia", "medo dos tratamentos", "quimioterapia" e "medo de voltar".

Após o diagnóstico, a mulher se vê frente aos tratamentos. Neste momento, os medos, inclusive da morte, continuam presentes e fazem com as mulheres prefiram iniciar precocemente os tratamentos para alcançarem a cura o quanto antes ${ }^{10,19}$.

A mastectomia carrega consigo uma representação muito significativa no tratamento do câncer de mama e é vivenciada por cada mulher de forma individual ${ }^{8,15,18}$. Quatro entrevistadas afirmaram sentirem medo em relação à cirurgia. Dessas, uma relatou o temor de uma infecção; outra, o receio de ficar acamada. Porém, seis entrevistadas não citaram medo. Essa ausência de medo pode estar relacionada à simbologia na qual a retirada da mama aparece como uma troca pela vida, como solução do problema para sua sobrevivência ${ }^{19}$.

Quanto aos tratamentos, o medo da quimioterapia foi citado por cinco mulheres. As reações negativas frente a essa terapêutica emergem pelos efeitos colaterais desencadeados por ela e que interferem na imagem corporal e na vida das mulheres ${ }^{6,8}$. Dentre estes efeitos, o mais temido é a queda do cabelo, por ser uma representação da feminilidade mais visível do que a própria mama ${ }^{9,19}$. No entanto, assim como a cirurgia, os tratamentos também podem ser encarados de outra forma e aceitos por fazerem parte do processo de cura ${ }^{19}$, como demonstrado nos recortes das falas das participantes.

[A quimioterapia] foi meu maior medo. Eu não acostumava de jeito nenbum. (E3)

Eu tinha aquela coisa assim, medo de morrer na bora da quimioterapia. Eu tinba medo na bora que eu ia fazer. Eu sentava e falava assim: "Meu Deus, entra aqui". (E4)

Sinceramente, eu não tive medo. Eu simplesmente me entreguei ao tratamento. (E9)

Outro receio que surge é o da recidiva do câncer ou de metástases. Contudo, essa preocupação varia de uma pessoa para outra, influenciada pelas experiências vividas, pelas estratégias de enfrentamento e a rede de apoio de cada mulher ${ }^{8,19}$.

Acho que esse é o medo, acho que de todo mundo [...], porque eu já sabia que estava [com câncer] bá um tempinbo, e o medo era se ele tivesse espalhado para algum lugar. (E9)

Meu maior medo é quando a gente vai fazer os exames, com medo de ter ido para algum órgão. [...] Cada exame que eu fazia, eu ficava com medo de ter ido para algum órgão. (E10)

Diante dos tratamentos, o corpo se fragiliza, os temores emergem, a possibilidade de recidiva da doença ronda os pensamentos da mulher, os efeitos das terapêuticas se exacerbam, trazendo repercussões físicas, psicológicas e sociais. Portanto, após o diagnóstico, a rede de apoio se faz fundamental para dar suporte e favorecer o enfrentamento do processo de adoecimento e recuperação, visando a minimizar o impacto do câncer de mama em suas vidas.

\section{IMAGEM CORPORAL}

As subcategorias que deram origem a essa categoria foram: "impacto da retirada", "mudanças no corpo", "mudanças na região da cirurgia", "queda do cabelo", "sob o olhar do outro", "peso", "reconstrução da mama", "fisioterapia" e "imagem corporal".

Inicialmente, a retirada da mama pode ser vista como a solução para o problema. Porém, com o afastamento das possibilidades de morte, o câncer assume a forma de doença crônica, e essas mulheres percebem que ele não necessariamente acabou'. Daí surge a preocupação com a mutilação associada aos efeitos dos demais tratamentos ${ }^{8,10,17}$.

A mastectomia pode provocar diferentes reações de acordo com a forma com que cada mulher conviveu com seu corpo ao longo de sua vida e o significado atribuído a ele, no contexto social onde cada uma está inserida $^{4,8}$. Para nove entrevistadas, a mastectomia representou uma mutilação, traduzida como "está faltando algo", a perda de um órgão representativo da identidade feminina, que lhes causou tristeza e vergonha dentre outros sentimentos. 
Fiquei sem ela [mama], e olhar para ela faz muita falta, né? Ainda mais se for nova, é pior ainda. (E2)

[...] Foi Deus que me deu [a mama], e aí o câncer vem e tira ela de mim. Então é 100\% falta, entendeu? É um pedaço de você que arrancou. (E4)

[...] A gente vê que está faltando alguma coisa, né? A gente vê que está faltando um pedaço, sei lá, eu não gosto de olbar. (E9)

Além da mastectomia em si, podem ocorrer complicações e ficar sequelas ${ }^{3,7}$. A cirurgia traz outras consequências que afetam a vida dessas mulheres, como observado neste estudo: cicatrizes, falta de sensibilidade, edema, dor, alterações posturais, além de limitação e medo de movimentar o braço ipsilateral à cirurgia ${ }^{7,12,13}$. No GI, surgiu ainda a dificuldade em encontrar roupas adequadas:

[...] Às vezes, é uma roupa que você coloca, vocêfica incomodada se estiver aparecendo. [A gola] tem que ser mais alta. Tem que trocar o jeito da roupa. Então, essas coisas que incomodam. (E9)

O corpo imperfeito, de acordo com os padrões socioculturais, resultado da mastectomia e dos tratamentos, provoca sentimentos de tristeza e de estranheza, que podem ser reforçados pelo olhar do outro ${ }^{4,8}$. Para a maioria das entrevistadas que passou pela quimioterapia, essa foi a pior parte do tratamento. $\mathrm{O}$ impacto da perda de cabelo, além de ocorrer de forma súbita, se trata de algo visível, expondo ainda mais a doença e a mulher acometida, interferindo em sua autoestima $^{8,19}$. Cinco das entrevistadas demonstraram essa preocupação de como os outros as veem:

[...] O cabelo também é a vaidade da mulber [...]. É aquela coisa que, às vezes, é um intimo seu, que vem, você fala que aceita, você sabe que tem que passar por aquilo tudo..., mas também não éfácil. (E2)

[...] aconteceu de eu estar em certos lugares e ver pessoas: "Ela não tem a mama, é uma mulher sem mama". Rapazes, tipo assim, bomens olhavam para mim: "Nossa ela não tem uma mama”. (E4)

Nossa, foi triste... a pior coisa [...]. Acho que foi pior do que tudo [...]. Sabia que eu tinha que pensar na saúde, que eu estou viva, mas acho que acumulou tudo. E acho que a mulher sempre tem essas coisas de cabelo, né? A vaidade. (E10)

Com o objetivo de reduzir o trauma da mutilação e melhorar a percepção da autoimagem das mulheres, surge a opção da reconstrução da mama ${ }^{1,5,9}$. Trata-se de um ato cirúrgico para reparação que pode ser imediato à mastectomia, ou tardio ${ }^{1}$. No presente estudo, cinco mulheres não realizaram a reconstrução e, das cinco que fizeram, duas foram imediatas e três tardias. Do GI, duas expressaram o interesse em fazer essa cirurgia, sendo que a de E9 já estava até marcada.

\begin{abstract}
Eu só queria mesmo fazer a reconstituição para ver se eu paro com a vergonha. Igual eu falei, eu não vou mais a praia, não vou mesmo a lugar nenbum. Ter que tirar a roupa não é a minha praia mais. (E1)
\end{abstract}

Me incomoda; por isso, que eu quero fazer a reconstrução. (E9)

O medo de uma nova cirurgia, possíveis complicações ou rejeição, e novas dores influenciam na tomada da decisão quanto à reconstrução da mama. Muitas mulheres não aderem a essa opção terapêutica por se tratar de um processo que pode ser longo, complicado e doloroso, que necessita de novas etapas operatórias que podem gerar complicações ${ }^{5,19}$.

\begin{abstract}
Eu não estou preparada. Eu tenbo muito medo. Sofri muito quando eu tirei. Falei com Deus. Se ele me curasse, eu não ia ligar para estética. (E3)
\end{abstract}

A falta de interesse em fazer a reconstrução também pode estar relacionada a uma relação estável com seu parceiro ${ }^{5,19} \mathrm{e}$ ao fator idade, isto é, quanto maior a idade da mulher, menor é a possibilidade de ela optar pela cirurgia ${ }^{5}$. No presente estudo, pode-se observar que três entrevistadas do GI e uma do GII não possuíam um companheiro.

\footnotetext{
Não preciso me preocupar, agora, se eu fosse, assim, na sua idade, mais jovem, eu me preocuparia. Hoje não, boje, pra mim, não faz falta, não. (E2)
} 
Com os avanços da cirurgia plástica, os resultados dessa intervenção cirúrgica vêm sendo cada vez mais satisfatórios, possibilitando às mulheres reconquistarem sua feminilidade e sensualidade, convivendo melhor com esse novo corpo ${ }^{5,8,19}$. Em alguns casos, a nova mama não consegue atingir as expectativas, uma vez que é artificial5, ou seja, não é "a verdadeira"19.

[...] Eu sabia que eu estava com uma coisa
que já não era minha mais. [...] Eu gosto
muito de usar decote, os outros falam
assim: "Nossa, você está com um peito
bonito", aí eu falo assim: "Pena que não é
meu". (E5)

Além da cirurgia, outro recurso alternativo para substituir esse órgão tão importante é a prótese externa, a fim de "preencher esse vazio". No presente estudo, todas as mulheres sem reconstrução mamária (GI) faziam uso de algum tipo de prótese externa. Esse recurso é utilizado como alternativa para contornar a perda, tão perceptível ao olhar do outro?.

As alterações posturais e limitações das atividades cotidianas são frequentes após a mastectomia ${ }^{7,12,13}$, pois essas mulheres, principalmente as sem reconstrução, além das restrições de movimento do braço homolateral à cirurgia, adotam posturas viciosas, seja pela dor ou pela vergonha da mutilação ${ }^{12,19}$.

[...] A postura da gente fica diferente. Você custa aceitar, porque aquilo parece que dá um vazio, te traz assim, sabe, o contrário; $o$ corpo pesa o contrário. (E2)

[...] Às vezes, eu tenho que me corrigir, porque é como se eu estivesse andando corcunda para poder esconder. (E9)

Todas essas alterações também provocam disfunções psicoemocionais, pela falta de preparo para se adaptarem à sua "nova imagem", provocando modificações na percepção da imagem corporal das mulheres ${ }^{9}$. Adaptar-se às limitações requer um enorme esforço, e as dificuldades desse momento as desestabilizam ${ }^{4,17}$.

[...] Eu tenho vergonba de mim mesma. Mais de mim do que dos outros [...]. Eu não fico em frente a um espelbo, jamais
[...]. Eu me acho gorda, eu me acho feia, eu acho meu cabelo feio, en acho essa cirurgia borrorosa; então, eu prefiro não ter esse impacto de ficar olhando no espelbo [...]. Acho que nem me vejo como mulber. (E1)

Me sentia assim... pior, né? Me sentia borrivel, né? Sem sobrancelha, sem pelo nenbum, né? Me sentia um monstro. (E10)

A imagem corporal se torna motivo de apreensão, resultando em mudanças no cotidiano, como não querer ver-se no espelho, evitar se tocar e, ainda, ter vergonha de si mesma e das outras pessoas ${ }^{8,9}$, interferindo também na própria representação do feminino ${ }^{17}$. Como alguns autores destacam ${ }^{4,13,19}$, além da imagem corporal, as limitações na funcionalidade podem gerar sentimentos de incapacidade $^{19}$ que interferem no autoconceito, prejudicando ainda mais a qualidade de vida das mulheres acometidas pelo câncer mamário ${ }^{4,6}$.

\section{PAPEL NA SOCIEDADE}

A categoria "Papel na sociedade" foi estabelecida a partir das seguintes subcategorias: "Tarefas diárias", "Participação social", "Família" e "Relacionamento".

Além das limitações físicas e da fragilidade psicológica, surgem também as limitações sociais ${ }^{4,19}$. Sá e Pinheiro-Carozzo ${ }^{4}$ destacam que a abstinência das atividades laborais pode interferir negativamente nas relações sociais e na autoestima, já que o trabalho é visto como uma realização, além de afetar a renda familiar. As mulheres têm de diminuir ou abandonar suas tarefas do dia a dia, como trabalhar e cuidar da casa ${ }^{12}$. Dentro da família, veem os papéis se inverterem, pois deixam de ser "cuidadoras", para receberem o cuidado ${ }^{6,17}$, como representado nas falas a seguir.

[...] Sempre fui de não pedir a ninguém para fazer qualquer coisa. Eu que sempre fazia tudo, então, isso incomoda [...]. Porque eu acho que atrapalba no meu jeito de viver. (E1)

[...] Não posso mais arrastar um móvel, não posso mais cortar um cabelo, que eu gostava de cortar o cabelo da família. Não posso mais pegar um peso, aí, tem que ficar pedindo, e eu não gosto muito de ficar pedindo [...]. Ficou mais dependente. (E9) 
Além de todas suas limitações e sequelas, as dificuldades desse momento as desestabilizam e podem impactar em suas relações intrapessoais e interpessoais ${ }^{4}$. Fora de casa, elas podem ver o comprometimento de suas relações pessoais, levando, em alguns casos, ao isolamento ${ }^{4,12,17}$. Cinco das entrevistadas relataram que deixaram de sair ou evitaram o convívio social em, pelo menos, algum momento do tratamento. Algumas se isolaram, enquanto outras se sentiram isoladas.

Entre os amigos, tinha dia que eu não estava pra ouvir conversa. Tem dia que você não está nem para ouvir a voz dos outros, que te irrita. (E2)

Faziam festa e não convidavam [...]. A sensação que eu tive foi essa, que você deixa de fazer parte, um pouquinbo, da sociedade. (E4)

Conforme já descrito, a maioria dessas mulheres teve o apoio da família. Elas relataram que a doença os aproximou mais, fazendo com que se sentissem protegidas e cuidadas ${ }^{17,19}$. Porém, algumas participantes relataram que, para os familiares, é mais difícil lidar com a doença e, alguns casos, essa não aceitação acaba refletindo negativamente em seus relacionamentos.

O meu menino mais velbo não tem aceitação até boje também, tem muito problema comigo em relação a isso, porque ele não aceita. (E4)

Como vários estudos demonstraram, a imagem corporal também está relacionada à sexualidade ${ }^{4,6}$. Os efeitos dos tratamentos desencadeiam alterações na percepção da imagem corporal ${ }^{3,4}$ e da identidade feminina ${ }^{9,11,16}$. Uma visão alterada de si mesma e de seu corpo gera um sentimento de vergonha que acaba por refletir na vida sexual dessas mulheres ${ }^{5}$, como explicitado nas falas abaixo.

Eu só estou assim, mais fechada para um novo relacionamento. Eu não sei assim, se eu vou ter coragem de ter outro relacionamento. (E5)

[...] Eu vi muitos casos que mulberes esfriam, não querem mais ter relação sexual. (E4)
A reintegração social e familiar da mulher mastectomizada e sua readaptação às novas condições facilitam a aceitação de seu novo corpo, promovendo uma melhora da imagem corporal e sexualidade e, consequente, melhoria na qualidade de vida.

\section{CONSIDERAÇÕES FINAIS}

Além de avaliar a percepção da imagem corporal de mulheres mastectomizadas, com ou sem reconstrução mamária, este trabalho possibilitou melhor compreensão do impacto do câncer de mama em suas vidas, desde o diagnóstico da doença, aos medos, temores e expectativas das mulheres durante todo esse processo. Examinou como elas lidam com os tratamentos e suas sequelas, sua decisão de realizar ou não a reconstrução da mama, até as repercussões físicas, psicológicas e sociais que todas essas mudanças lhes trazem.

O diagnóstico desperta reações emocionais complexas, por se tratar de uma doença ainda estigmatizada pelo medo da morte e da recidiva. O processo de enfrentamento é singulare reflete a história de cada mulher, sendo a atitude de aceitação ao diagnóstico e aos tratamentos uma possibilidade de tornar essa jornada menos dolorosa. Neste sentido, a rede de apoio é fundamental para que esta mulher tenha o suporte emocional necessário, visando de minimizar os impactos do câncer de mama. Observa-se que as alterações físicas e psicológicas refletem, ainda, em problemas sociais e sexual, uma vez que a maioria dessas mulheres abdicam de seus trabalhos, evitam sair de casa, têm suas tarefas diárias afetadas. O câncer pode provocar nelas a sensação de inutilidade e dificuldade de adaptação à sua nova imagem, evidenciando a complexidade das mudanças que ocorrem em suas vidas.

Ressalta-se, como limitações deste estudo, o fato de as participantes terem sido escolhidas por conveniência e, ainda, serem atendidas no ambulatório de Fisioterapia do local onde o estudo foi realizado. Entretanto, acredita-se que os resultados da presente pesquisa possibilitam ampliação da discussão teórica acerca do tema, bem como contribuem para melhorias na rede de atenção às mulheres com câncer de mama.

A partir disso, conclui-se que o cuidado com a 
saúde desse público-alvo demanda maiores investimentos em pesquisas e ações em saúde com características interdisciplinares, que viabilizem espaços de reflexão, integração e convivência para essas mulheres. Pesquisas e ações que auxiliariam no processo de enfrentamento da doença e reabilitação para além das limitações físicas, devem ser feitas, com o intuito de reconexão com o corpo físico, psíquico e espiritual.

Deste modo, os profissionais de saúde devem atuar de modo articulado, levando em consideração a participação das usuárias nas tomadas de decisão. Devem esclarecer suas dúvidas e promover maior conhecimento às mulheres sobreviventes ao câncer de mama acerca do adoecimento e seus impactos, a fim de facilitar uma adaptação a esse "novo corpo" e permitir o retorno precoce dessas mulheres às suas funções e tarefas cotidianas, o que possibilitaria um incremento na autoestima e na imagem que representam de si, sua reinserção na sociedade e melhora da qualidade de vida.

\section{REFERÊNCIAS}

1. Ministério da Saúde (BR). Instituto Nacional de Câncer José Alencar Gomes da Silva. A situação do câncer de mama no Brasil: síntese de dados dos sistemas de informação. Rio de Janeiro (RJ): Ministério da Saúde. Instituto Nacional de Câncer José Alencar Gomes da Silva; 2019.

2. Ministério da Saúde (BR). Instituto Nacional de Câncer José Alencar Gomes da Silva. Coordenação Geral de Ações Estratégicas. Coordenação de Prevenção e Vigilância. Estimativa 2018: Incidência de câncer no Brasil. Rio de Janeiro (RJ): Ministério da Saúde. Instituto Nacional de Câncer José Alencar Gomes da Silva. Coordenação Geral de Ações Estratégicas. Coordenação de Prevenção e Vigilância; 2017.

3. Brochonski JW, Rodrigues S de A, Manzotti CAS, Bernuci MP. Perfil das mulheres diagnosticadas com câncer de mama no município de Maringá-PR. Saúde e Pesquisa. 2017;10(1):51-58.

4. Sá GS, Pinheiro-Carozzo, NP. Imagem corporal e habilidades sociais em pacientes com câncer de mama. Rev Psicol IMED. 2018;10(1):37-55.
5. Inocenti A, Santos MA dos, Loyola EAC de, Magalhães PAP de, Panobianco MS. Repercussão dos efeitos da cirurgia reconstrutora na vida de mulheres com neoplasias da mama. Texto \& Contexto Enferm. 2016;25(2):1-9.

6. Oliveira FBM, Santana e Silva F, Prazeres ASB dos. Impacto do câncer de mama e da mastectomia na sexualidade feminina. Rev Enferm UFPE on line. 2017;11(supl.6)2533-40.

7. Gokal K, Wallis D, Ahmed S, Boiangiu I, Kancherla $\mathrm{K}$, Munir F. Effects of a self-managed home-based walking intervention on psychosocial health outcomes for breast cancer patients receiving chemotherapy: a randomised controlled trial. Support Care Cancer. 2016;24(3):1139-66.

8. Silva MB da, Pessoa Júnior JM, Miranda FAN de. Trajetória de vida de mulheres mastectomizadas à luz do discurso do sujeito coletivo. Rev Pesqui Cuid Fundam. 2016;8(23):4365-4375.

9. Almeida TR, Filgueiras MST. O que Narciso acha feio: corpo ideal e a imagem corporal no câncer de mama. In: Filgueiras MST, Faria HMC, Almeida TR, organizadoras. Câncer de mama: interlocuções e práticas interdisciplinares. Curitiba: Appris; 2018. p. 119-138.

10. Dias LV, Muniz R, Viegas ADC, Cardoso DH, Amaral DEDD, Pinto BK. Mulher mastectomizada por câncer de mama: vivência das atividades cotidianas. Rev Pesqui Cuid Fundam. 2017;9(4):1074-1080.

11. Adorna E da L, Morari-Cassol EG, Ferraz NMS. A mastectomia e suas repercussões na vida afetiva, familiar e social da mulher. Saúde (Santa Maria). 2017;43(1):163-168.

12. Costa ID, Santos DHO, Silva V de M, Chaves CMCM, Silva FC, Pernambuco AP. Utilização de um Core Set da CIF para a descrição da atividade e participação de mulheres submetidas ao tratamento cirúrgico para o câncer de mama. Revista Interdisciplinar Ciências Médicas. 2018;2(1):4-14.

13. Ibrahim MMT, Smirnow N, Sateren W, Fournier B, Kavan P, Palumbo M, et al. Time course of 
upper limb function and return-to-work postradiotherapy in young adults with breast cancer: a pilot randomized control trial on effects of targeted exercises program. Journal Cancer Surviv. 2017;11(6):791-799.

14. Recchia TL, Prim AC, Luz CM da. Upper limb functionality in quality of life in women whith fiveyear survival after breast cancer surgery. Rev Bras Ginecol Obstet. 2017;39(3):115-122.

15. Koch MO, Zamian R, Victor GLG, Segura DCA. Depressão em pacientes com câncer de mama em tratamento hospitalar. Rev Saúde e Pesquisa. 2017;10(1):111-117.

16. Farias LMA, Aguiar VCF, Carvalho AMF de, Linhares JM, Linhares AEMS, Sousa MM de. Grupo de mulheres mastectomizadas: construindo estratégias de cuidado. SANARE. 2015;14(2):91-97.

17. Martins ARB, Ouro TA do, Neri M. Compartilhando vivências: contribuição de um grupo de apoio para mulheres com câncer de mama. Rev Sociedade Brasileira de Psicologia Hospitalar. Rio de Janeiro. 2015;18(1):131-151.

18. Ferreira RMB, Lemos MF. A mulher e o câncer: um olhar sobre o corpo adoecido. Perspectivas em Psicologia. Uberlândia (MG). 2016;20(1):178-201.

19. Carvalho SM, Tolomelli FA, Gusmão AL, Grincenkov FRS. Corpo, funcionalidade, espiritualidade e câncer de mama. In: Filgueiras MST, Faria HMC, Almeida TR, organizadoras. Câncer de mama: interlocuções e práticas interdisciplinares. Curitiba: Appris; 2018. p. 137-155.

20. Minayo MCS. O desafio do conhecimento: pesquisa qualitativa em saúde. $14^{\mathrm{a}}$ ed. São Paulo: HUCITEC; 2014 .

21. Bardin L. Análise de Conteúdo. $70^{\mathrm{a}}$ ed. São Paulo: Martins Fontes; 2016.

22. Brasil. Ministério da Saúde. Conselho Nacional de Saúde. Resolução no 466, de 12 de dezembro de 2012. Diretrizes e normas regulamentadoras para pesquisas com seres humanos. Diário Oficial da
União, Brasília, 13 jun. 2013. Seção 1, p.59.

Recebido em: 28/05/2019

Aceito em: 20/08/2019 